\title{
Fertility and Family Formation. Some Trends among Danish Female Cohorts Born between 1932 and 1967
}

\author{
HANS OLUF HANSEN \\ DAN ROHRMAN
}

\section{Introduction}

Knowledge of family formation and understanding of reproductive behavior have become increasingly pertinent in the contemporary Nordic societies including Greenland. A number of impacts of the declining fertility and the changing patterns in cohabitation are now beginning to be felt and are subject to rising concern in many curricula and in the public.

The most recent Danish fertility survey was carried out in 1975 by Socialforskningsinstituttet (The Danish National Institute of Social Research; hereafter abbreviated SFI). This survey has been subject to deep-going and innovative analyses of cohabitational birth spacing based on life table methods, cf. Finnäs and Hoem $(1979,1980)$ and Hoem and Selmer (1982). A wider variety of aspects of the 1975 fertility survey were analyzed by Bertelsen (1981) and Ussing (1979). An important study of B. Hoem (1979) entailed estimation of parity-specific birth intesities using cumulative incidence rates according to methods expounded by Hoem (1978) and Finnäs (1980). The estimates were based on published and unpublished Danish official statistics. In the absence of more recent Danish life history data concerning family formation (through live birth, and formation and dissolution of marriage and consensual unions) on the level of individual females the approach adopted by B. Hoem (1979) was continued by Rohrmann (1983) on essentially the same type of data basis. The Rohrmann-study also included cohort estimates of marital and nonmarital fertility and intensities of formation and dissolution of marriage for Danish females born between 1932 and 1967. At the risk of stretching the analysis beyond the restrictions imposed by the underlying statistical model an attempt was made to estimate parity-specific fertility rates for single women born between 1947 and 1967.

The following account draws on tables and graphs prepared for the study of Rohrmann (1983). To create an aperçu of the structures and trends displayed by the various estimated intensities, cumulative hazards were established and plotted as function of birth year (calendar time) and age. In this respect valuable inspiration was received from a study of Swedish cohort fertility by Johansson (1983). In the base report (Rohrmann 1983) asymptotic standard deviations were estimated wherever possible, both of the estimated intensities and of the cumulative hazards. Statistical testing has not been attempted up to now, partly because such efforts may be inopportune with the given data, and partly due to time constraints imposed on the project from various quarters.

In the following we present a few descriptive graphs concerning the annual number of live births between 1901 and 1982 and cumulative fertility rates at selected ages of the female cohorts born between 1901 and 1962 . Contour plots of the various cumulative incidence rates and fertility hazards are displayed further in this paper. A number of marital fertility differentials are discussed, and parity- 
specific fertility of all women (i.e. aggregated over marital status) and of single women are mentioned. Further, some cohort changes in formation and dissolution of marriage are considered. Finally some wider perspectives for research in Danish fertility are pointed out.

\section{Development of the annual number of live births and of the annual rate of total fertility (TFR) from 1901 to 1982, and some fertility changes of the female cohorts born between 1901 and 1962}

The annual number of live births from 1901 to 1982 is shown in Figure 1. Period estimates of the corresponding annual total fertility rates are given in Figure 2 (Figures $1-6$ on p. 36).

The temporary increase of the birth figures in 1920 and 1921 (Figure 2) may, at least to some extent, be due to data problems in connection with the reunion of North Slesvig with Denmark on June 15, 1920. A steady decline in the annual live births reached a preliminary minimum in 1933 at the bottom of the economic depression (62,780 live births). It was replaced by an increase culminating in 1946 with 96,111 live births which is the highest annual birth figure ever recorded in Denmark up to now. The temporary increase in the annual birth figures during 1959 to 1966 possibly emerges as an echo of the big cohorts born during, and shortly after, World War II. The annual changes in TFR appear to have been small between 1949 and 1966 (Figure 2) and are thus in consonance with the echo hypothesis. The annual rate of total fertility dropped from 2.615 in 1966 to 1.427 in 1982 (1983: 1.38). By 1983 the birth number had fallen to 50,878 (preliminary figure).

It is well known that application of period estimates of fertility may be severely misguiding for analytic purposes. For this reason the cohort approach will be adopted in the following. The greater part of the official Danish statistics represents observation on period basis, at least prior to 1968, cf. Rohrmann (1983, chapter 3 ). In addition aggregates of individual exposure times are unavailable in official statistics. The following analysis therefore entails application of common demographic approximation techniques with regard to estimation of central rates and incidence rates on cohort basis. Showing the cumulative fertility rates at selected ages of the one-year cohorts born between 1901/02 and 1962/63 the graphs displayed in Figure 3 also provide a longer historical perspective for the analyses presented in the following paragraphs.

The completed fertility has been subject to a minor increase over the cohorts born between 1903/04 and 1930/31. The age pattern of the fertility of the generations born during the $1930 \mathrm{~s}$, moreover, is relatively more skewed to the left i.e. downwards in age. Although the completed fertility cannot be observed beyond the cohorts of the 1930s there are strong indications that it will be subject to decrease over the following generations. The fertility decline should not be appreciated too naively, however. Note, for example, that the cumulative cohort birth rate by age 30 as of 1981 is already nearly on a par with the estimated rate of total fertility for 1981. It is also of interest to observe that the cohorts born around 1910 in their more mature ages compensated for the low fertility level in their younger ages during the $1930 \mathrm{~s}$. These cohorts ended up with a completed fertility which is not remarkably low compared to that of the neighboring cohorts.

\section{Some trends in age-specific fertility by marital status and parity}

To provide a comprehensive overview of the cohort aspects and the calendar trends in fertility and to ensure comparability with the Swedish study of 

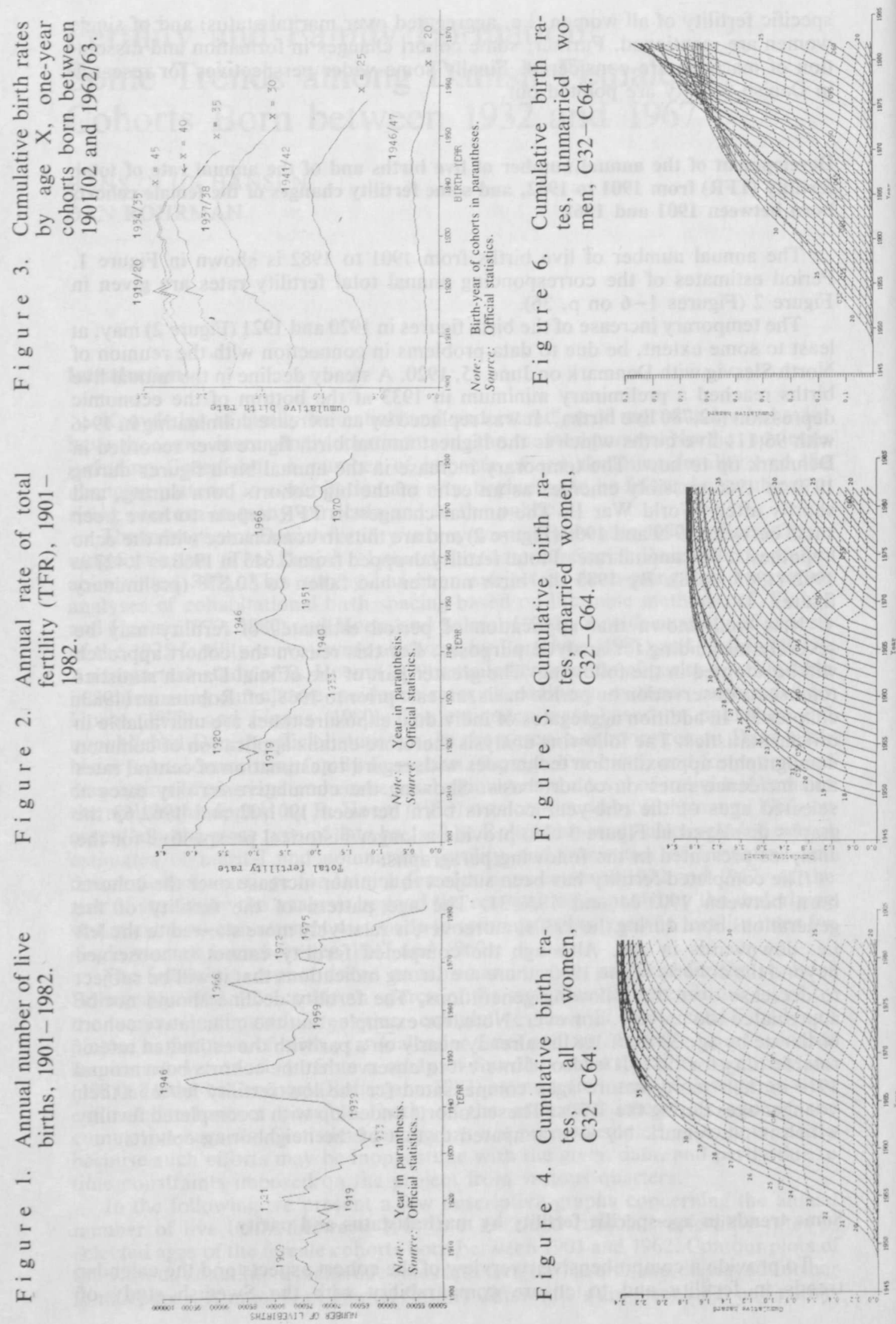
Johansson (1983) the cumulative hazards pertaining to one-year cohorts have been plotted as function of birth year (calendar time) and birthdays included in the age interval of childbearing. Successive cumulative hazards of any given cohort are connected with straight lines (»cohort lines») and so are the cumulative hazards at any given birthday over successive cohorts ("age lines»). As far as the fertility of all women born between 1931/32 and 1963/64 (i.e. C32 and C64) are concerned, the result is shown in Figure 4.

It will easily be recognized that whenever fertility remains constant over the cohorts considered, all age lines will be parallel with a slope equal to zero. Fall in a cumulative rate at a given age from one cohort to another induces an age line with negative slope, and increase in a given cumulative rate leads to the opposite. Change in a given age-specific rate from one cohort to the following will effect non-parallel age lines for the age intervals considered. The last-mentioned type of change may, admittedly, in some instances be difficult to detect, and that is a drawback of the graphic method used here.

The surface displayed in Figure 4 shows a consistent fall in cumulative fertility at all ages during the 1970s starting around 1963/64.

The fertility of all women refers to a highly heterogeneous population. To reduce this heterogeneity we have produced similar surfaces for married and unmarried women (Figures 5-6).

That formal marital status should be a variable of little or no importance for the study of contemporary Danish fertility is effectively contradicted by the reproductive experience presented in Figures 5-6. Depending on the way of comparing, the fertility of the married women is about 4-7 times higher than that of unmarried females. The differences are considerable, even for the younger cohorts.

The cumulative fertility rates of married women display a high persistency up to the late 1960 s. Then a substantial decrease in cohort fertility becomes evident. A new temporary stability is discernible for the cohorts born in 1951 and later. The younger cohorts attain a relatively low and slowly decreasing cumulative marital fertility as far as the observable life segments are concerned. It is interesting to observe the agreement of these findings with tendencies recognized by Hoem and Selmer $\left(1982\right.$, p. $\left.1,6^{\circ}\right)$.

Though justifiable within the framework of the underlying statistical model we emphasize that the cumulative fertility hazards of the married state should not be interpreted as expected family size of a woman being married throughout her fertile age span. One important reason is, of course, lack of homogeneity with respect to duration of marriage within a group of married women of a given age.

For the reason mainly of editorial restrictions we abstain from examining the cohort fertility of widows and divorcees. We shall restrain ourselves to consider the cohort fertility of unmarried women (i.e. single females, widows and divorcees) though lumping three marital statuses together means introduction of undesirable heterogeneity. An alternative option would have been to concentrate on the cohort fertility of single women. The contour plot of the cohort fertility of unmarried women is shown in Figure 6.

Contrary to marital fertility there has been a considerable upsurge in the cumulative cohort fertility of unmarried women from age c. 22 and older, in particular for the cohorts born after c. 1940/41. Although impossible to prove with the given data this development must almost certainly be connected with the increasing occurrence of non-marital cohabitational unions since the beginning of the 1960s. For evidence of the increase of the so called 'paperless marriages' cf. Dinesen (1976) and Danmarks Statistik (1977, 1978, 1980-1982). The studies by Finnäs and Hoem $(1979,1980)$ and Hoem and Selmer (1982) based on the Danish fertility survey, 1975, and the studies of Hoem and Rennermalm (1982) (based on Swedish data) and of Selmer (1983) (based on the Norwegian fertility survey, 1977), altogether provide a basis for suggesting that non-cohabiting single 
women have a much lower fertility than cohabiting single women, who on their side have a low fertility compared to that of married women. Note that by taking duration of status into account these authors present analyses which also in other respects are much more refined than the one attempted here.

Having considered shortly the cohort fertility of all women and of married and unmarried women (Figures 4-6) we now present estimates of parity-specific fertility based on cumulative incidence rates, partly for women aggregated over marital status, and partly for single females. As far as all women are concerned the present contribution may be seen as essentially an updating of the results presented by B. Hoem (1979). Concerning specification of the underlying statistical model and examination of some statistical properties of the applied estimators we refer to Hoem (1978), Finnäs (1979, 1980), and Borgan and Ramlau-Hansen (1983). A comprehensive discussion of merits and limitations of the simple parity model and the use of incidence rates on appreciation of fertility may be found in B. Hoem (1979). Suffice it to mention that our estimation in the model of all women is based on an assumption of non-differential mortality with regard to parity. The state space of the model of single females will be outlined below along with the assumptions reguired for estimating in that model.

The cumulative incidence rate of a certain parity at a given age $\mathrm{X}$ is an estimate of the expected proportion of women alive at age $\mathrm{X}$ who attain the given parity and give birth at least to one additional child before age $\mathrm{X}$. The cumulative incidence rates and the derived cumulative (cohort) fertility rates of parity 0 (i.e. first-births) are shown in Figures 7-8. It appears that there has been a steady decline in the cumulative incidence of having at least one child, or phrased differently: childlessness has been steadily on the increase over all cohorts and birthdays considered. Consequently, the estimated cumulative fertility rates of first-births have decreased (Figure 8).

The cumulative incidence of second-births (Figure 9) shows a falling tendency and the cumulative hazards of having a second child are also falling (Figure 10); they seem, moreover, to be (slightly) higher than those of first-births (Figure 8).

The cumulative incidence of third-births (Figure 11) is falling over cohorts and is dramatically lower than that of second-births. The corresponding cumulative fertility hazards are falling and are generally low compared to the cumulative fertility hazards of first- and second-births.

The above-mentioned conclusions concerning some cohort trends in parity-specific fertility are supported on a more partial basis by the corresponding age-specific birth rates shown in Figures 13-14 (on p. 40); the birth rates refer to the cohorts born in 1945 and 1951 .

These developments have far-reaching impacts on composition of the family with regard to expected number of live-born children. To illustrate this point estimated expected cohort distributions of females by parity at selected ages are given in Appendix Table (see p. 45), partly for all women, and partly for single women.

As far as all women are concerned the tendency of having more than two children is decreasing at all ages. The growing tendency of staying childless is rather outspoken, too. Moreover, falling proportions of young women give birth to one and two children below age c. 24. After this age and age c. 30 the decline of the proportion of women being in parity 1 or 2 is brought to a halt for the observable cohorts. In other terms: having children is postponed to the more mature ages. This conclusion is supported by Figures $13-14$. Note that the proportion of women being in parity 2 by age 29 has been slightly declining over the youngest cohorts (C50, C51, and C52).

Finally we turn to the parity-specific cohort fertility of single women. The state space of the underlying statistical model is outlined in Figure 15. The states of 'death' and '1st marriage' are absorbing. Furthermore, to carry out estimation with the given data it will be required to assume non-differential mortality and 
Figure 13. Birth rates by age and parity, all women, C45.
Fig u re 14. Birth rates by age and parity, all women, C51.
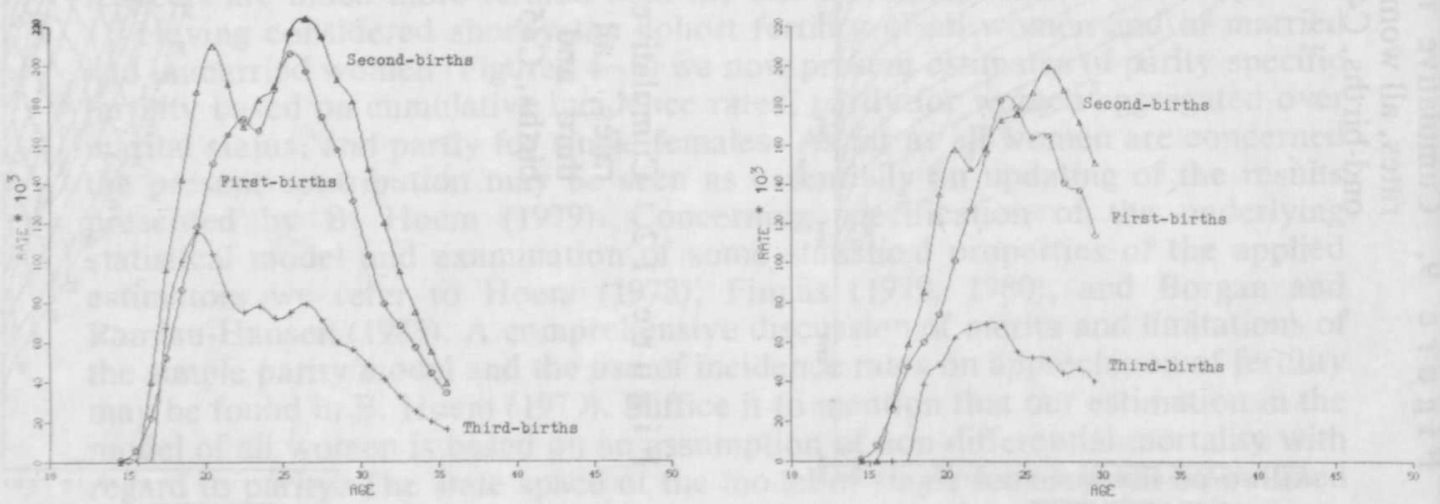

F i g u r e 15 . State diagram of model underlying the analysis of fertility by age and parity, single women.

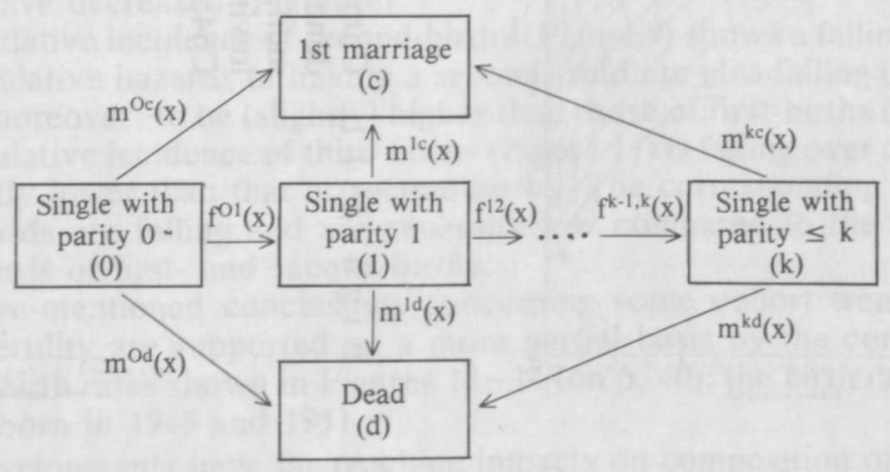

non-differential intensity of contraction of first marriage. The last-mentioned assumption probably is rather unrealistic, cf. Hoem and Selmer (1982, p. 24).

Examination of the robustness of the estimation in presence of alternative parity-specific intensity regimes for entering first marriage could be accomplished by calculating the corresponding multistate life table, cf. Hoem and Funck Jensen (1982). Such efforts are beyond the scope of the present study, however.

The cumulative incidence rates of first-, second- and thirdbirths of single women are shown in Figures 16, 18, and 20 respectively. The corresponding cumulative cohort-based birth rates are displayed in Figures 17 and 19.

Contrary to all women (cf. Figure 7) the proportion of single women staying childless up to a given age has been falling quite considerably over the cohorts considered, in particular in the more mature ages (Figure 16). In consonance herewith the cumulative rates of first-birth (Figure 17) have shown a distinct upswing. (Figures $16-21$ on p. 42) 
The cumulative incidence of second-births (Figure 18) has been falling in the ages below c. 28 , opposite to the older age groups. As far as the associated cumulative hazard is concerned, a very distinct change (fall) is discernible. It is interesting to note, moreover, that in contrast to all women the intensity by which a single female begets her second child is very much higher than that by which she gets her first child. Conjecturing that single women with parity 1 tend to marry with higher intensity than single women with parity 0 , the second-birth rate is likely to be under-estimated. The high rate of second-births is probably caused by selection of cohabiting "single" women on transition to the parity 1 state.

The cumulative incidence of third-births of single women has been steadily decreasing over all cohorts and ages considered. Due to smallness of numbers the corresponding cumulative fertility hazards were found to be too erratic for graphic representation. It will be sufficient to mention that few single women get three or more children any longer.

To obtain an overview of some aspects of fertility in the single state, estimated expected distributions by parity at selected ages are given in Appendix Table. The tendency of staying childless is decreasing in all ages. The inclination of having at least two children, however, has been low and rather stable among the cohorts born since the beginning of the 1950 s.

\section{Some cohort changes in formation and dissolution of marriage}

Since the fertility of all women is weighted with the marital distribution at each age and since fertility in marriage differs a lot from fertility in the unmarried state, it will be worthwhile to consider some aspects of formation and dissolution of marriage among the cohorts born between 1931 and 1966. Due to editorial restrictions cohort differences in mortality within and between the marital states will be bypassed along with cohort trends in external migration and transition to widowhood. As far as the last-mentioned topics are concerned we refer to Rohrmann (1983). The presentation and discussion in the following will be confined to the cumulative hazards of transition to first marriage (Figure 21) and to graphic representation of the first-marriage rates (Figure 22) and the divorce rates (Figure 23) for selected cohorts. (Figures 22-23 on p. 43)

The first-marriage rates seem to have increased from age c. 22 around 1965. In the late 1960 s this tendency was replaced by a rapidly decreasing inclination to enter the state of first marriage. The hazard curves show that the younger cohorts have a much lower marital intensity than the older cohorts (Figure 22).

There has been a considerable increase in the divorce rates from age c. 40 and older among the generations born after 1932. This upswing has been spreading downwards in age, in particular among the cohorts born c. 1940 and later (Figure 23).

Changes in formation and dissolution of marriage of the magnitude examplified in Figures 21-23 obviously have immmense impact on the fertility measured for all women, both on cohort and on period basis.

\section{Summary and some wider perspectives for research in Danish fertility}

In absence of more recent Danish fertility survey(s) than the one from 1975 the present study has been based on published and unpublished official statistical data. As a consequence of the limitations of the available data, the emphasis of the study has been on recorded behavior concerning childbirth and formation and dissolution of marriage. 

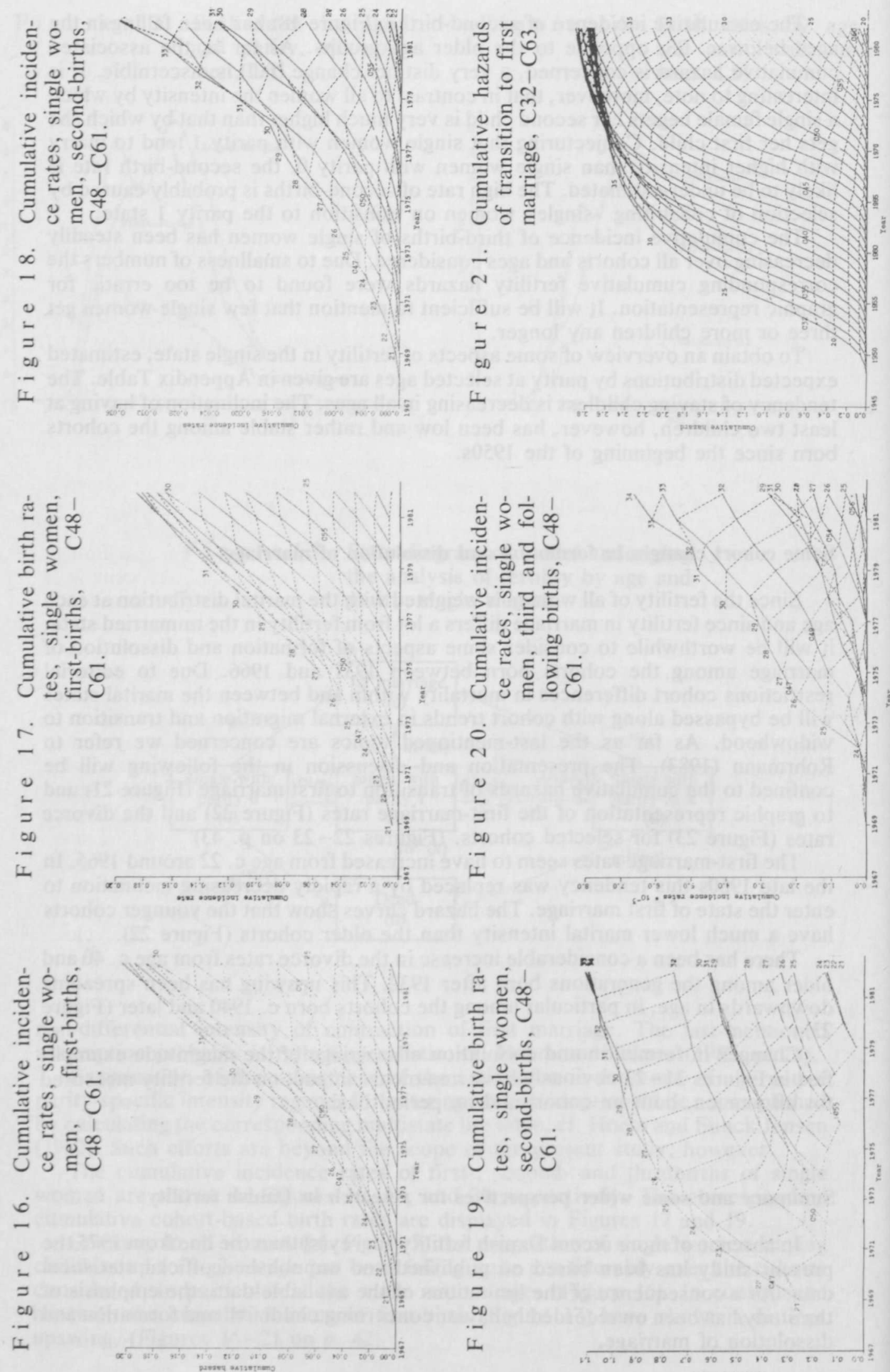
Figu re 22. Age-specific rates of transition to first marriage, cohorts $\mathrm{C} 32, \mathrm{C} 41, \mathrm{C} 50$ and C56.

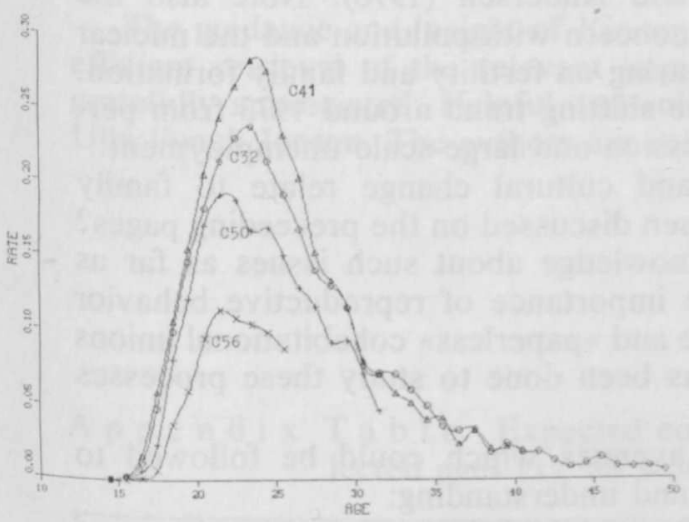

Fig u r e 23 . Age-specific rates of transition to the state of divorce, sohorts C32, C41, C50 and C56.

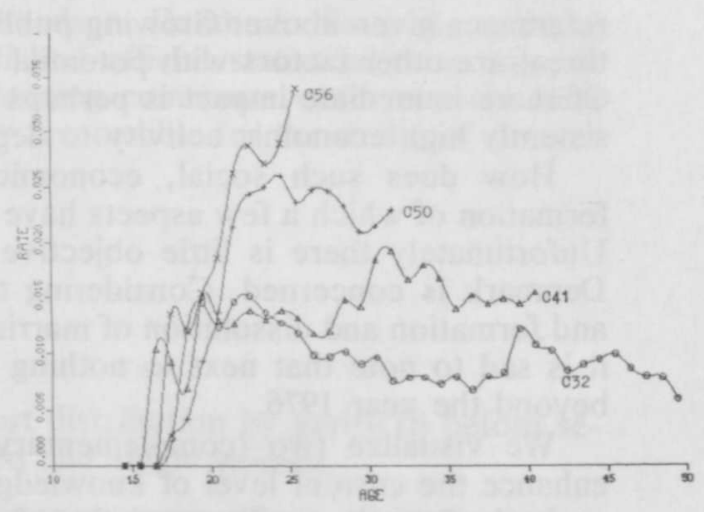

Some major conclusions reached by B. Hoem (1979) and Hoem and Finnäs $(1979,1980)$ were found to be tenable beyond 1975/76: Second-births occur with almost the same intensity as first-births, at least if all women are considered; the proportions of women staying childless up to given ages have been subject to continued increase, and there is a clear tendency to postpone childbirth to the more mature ages. Some other findings in earlier studies are impossible to consider due to shortcomings of the data available.

The present study has disclosed the existence of continued great differences in cohort fertility within, and between, the formal marital states considered. Women entering the childbearing ages after c. 1968 and being married have a much lower fertility in the observable age span than the cohorts born prior to c. 1950. At the same time the fertility of unmarried women has increased from age c. 22 among the cohorts born after 1940/41. Single mothers get second-births with a much higher intensity than first-births, probably due to selection of cohabiting "single" women on transition to the state of parity 1 .

That education, childbirth and occupational employment undoubtedly are interacting processes covering long and overlapping segments of the life cycle of the individual female are frequently made observations in the literature. Moreover, efficient and easily applicable means of contraception are readily available for the women and her sexual partner, and the right of having a pregnancy terminated by induced abortion before the 29th week has been established by law since 1973. Some annual statistics on provoked abortion are issued by Sundhedsstyrelsen (The Board of Public Health) and Danmarks Statistik (The Central Bureau of Statistics). Annual statistics on contraceptives sold are also published by Sundhedsstyrelsen. Application of contraception and provoked abortion have been subject to interesting survey-based studies by Ussing (1979) and Rasmussen (1983).

From the studies of Hoem and Fong (1976) and Strandmark (1982) and their references the working force participation of Danish women is known to have been subject to considerable increase during the 1970s. These studies are based on recurrent multi-wave panels of sample surveys on occupational employment carried out by Danmarks Statistik. Looking at the national population censuses this development may be traced back to the late 1950s. Since the beginning of the 1960 s, moreover, there has been a tremendous upsurge in the cohort proportion of 
women with General Certificate (Danish studentereksamen) entering universities and education of medium and long duration (cf. Rohrmann 1983). From the recurrent so called Omnibus-surveys carried out by Danmarks Statistik and Socialforskningsinstituttet the number of »paperless» cohabitational unions is known to have increased dramatically during the 1970 s. This phenomenon has been studied by Koch-Nielsen (1975) and Andersen (1976). Note also the references given above. Growing public concern with pollution and the nuclear threat are other factors with potential bearing on fertility and family formation. Of more immediate impact is perhaps the shifting trend around 1973 from persistently high economic activity to depression and large-scale unemployment.

How does such social, economic and cultural change relate to family formation of which a few aspects have been discussed on the preceeding pages? Unfortunately there is little objective knowledge about such issues as far as Denmark is concerned. Considering the importance of reproductive behavior and formation and dissolution of marriage and »paperless" cohabitational unions it is sad to note that next to nothing has been done to study these processes beyond the year 1976 .

We visualize two (complementary) avenues which could be followed to enhance the current level of knowledge and understanding:

In the first place a file consisting of data on childbirth, survivorship, change of formal marital status, and alteration of postal address, altogether at the level of individuals, could be extracted from the computerized National Population Register (CPR) established in 1968. Being created on sample basis or possibly on a total basis, and embracing the entire time span elapsed since 1968, or part of it, this life cycle information would represent observation in continuous time. The file should then be updated with additional individual life cycle data on occupational and employment status along with economic and habitational characteristics extracted from various other satellite registers established on computer basis from time to time during the 1970 s. The last-mentioned data types exist as observations in discrete time on sample basis or on total basis. Among the drawbacks of such a file would be lack of information on personal attitudes and preferences, participation in "paperless" cohabitational unions, application of contraception, abortion experience, etc.

To obtain information on attitudes and behavior not included in the general registers and to compensate for the considerable technical and professional skills required to extract more elaborate individual life cycle data from existing Danish population registers, resort may be taken to recurrent sample-based retrospective fertility surveys of the World Fertility Survey type. Such fertility surveys were carried out in Norway in 1976 and in 1981. A retrospective Swedish fertility survey was arranged in 1981.

Being based on population registers and/or retrospective sample surveys such life cycle data may be efficiently analyzed, amongst other techniques, with modern life table methods like those referred to in the first paragraph. In addition to the rich emerging literature on the subject, not least in Sweden and Norway, attention may be given to an analysis of Kenyan Fertility Survey data (WFS), $1977 / 1978$, by Jensen (1983). An important feature of the World Fertility Survey is openness and liberal access for interested researchers to the data created. Also in this respect the World Fertility Survey could serve as a model for other fertility surveys.

If Denmark is to avoid ending up as a backward country with regard to a wide range of demographic and social studies, it is about time that adequate life cycle data covering the recent years be provided. Recurrent collection of such information combined with analyses of the above-mentioned type could be hoped to provide a basis for more informed discussions of the background of the falling birth figures and for careful preparation and adjustment of desirable family policies. Although improved understanding of the Danish birth process does not 
ensure "perfect" population projections, it could indeed be an aid to prognosticators to erring more intelligently on forecasting population.

\section{Acknowledgements}

The guidance and insight of Kirsten Frandsen, Danmarks Statistik, enabling efficient retrieval of the relevant unpublished official statistical base data, is gratefully appreciated. Helpful and enlightening comments were received from Ulla Funck Jensen. The authors are solely responsible for the study, of course.

A p p e n d i x T a b l e. Expected cohort distribution by parity (i) before selected ages (x), all women and single women.

\begin{tabular}{|c|c|c|c|c|c|c|c|}
\hline \multirow{2}{*}{ Cohort } & \multicolumn{4}{|c|}{ All women, $\mathrm{i}=$} & \multicolumn{3}{|c|}{ Single women, $\mathrm{i}=$} \\
\hline & 0 & 1 & 2 & $3 \leq$ & 0 & 1 & $2 \leq$ \\
\hline \multicolumn{8}{|l|}{$x=20$} \\
\hline $\mathrm{C} 45$ & .7518 & .1972 & .0459 & .0051 & & & \\
\hline C46 & .7483 & .2012 & .0453 & .0051 & & & \\
\hline $\mathrm{C} 47$ & .7489 & .2037 & .0429 & .0045 & & & \\
\hline $\mathrm{C} 48$ & .7545 & .2040 & .0385 & .0030 & & & \\
\hline C49 & .7638 & .2003 & .0333 & .0026 & & & \\
\hline C50 & .7924 & .1770 & .0286 & .0020 & & & \\
\hline C51 & .8056 & .1632 & .0299 & .0013 & & & \\
\hline C52 & .8231 & .1496 & .0255 & .0018 & & & \\
\hline C53 & .8351 & .1418 & .0220 & .0011 & & & \\
\hline C54 & .8402 & .1401 & .0187 & .0010 & & & 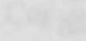 \\
\hline C55 & .8389 & .1406 & .0199 & .0006 & & & \\
\hline C56 & .8458 & .1542 & .0160 & .0005 & & & \\
\hline C57 & .8534 & .1306 & .0151 & .0009 & & & \\
\hline C58 & .8643 & .1214 & .0136 & .0007 & & & \\
\hline C59 & .8762 & .1110 & .0122 & .0006 & & & \\
\hline C60 & .8842 & .1046 & .0106 & .0006 & & & \\
\hline C61 & .8995 & .0910 & .0090 & .0005 & & & \\
\hline \multicolumn{8}{|l|}{$x=23$} \\
\hline $\mathrm{C} 45$ & .4611 & .3339 & .1726 & .0324 & & & \\
\hline $\mathrm{C} 46$ & .4842 & .3298 & .1573 & 0287 & & & \\
\hline C47 & .5032 & .3181 & .1523 & .0264 & .9864 & .0108 & .0028 \\
\hline $\mathrm{C} 48$ & .5167 & .3087 & .1511 & .0235 & .9845 & .0130 & .0025 \\
\hline C49 & .5210 & .3108 & .1476 & .0206 & .9792 & .0181 & .0027 \\
\hline C50 & .5456 & .3063 & .1291 & .0190 & .9781 & .0195 & .0024 \\
\hline C51 & .5479 & .3105 & .1255 & .0161 & .9761 & .0214 & .0025 \\
\hline C52 & .5621 & .3044 & .1174 & .0161 & .9725 & .0246 & .0029 \\
\hline $\mathrm{C} 53$ & .5732 & .3051 & 1097 & .0120 & .9736 & .0239 & .0025 \\
\hline C54 & .5954 & .2906 & .1022 & .0118 & .9725 & .0253 & .0022 \\
\hline C55 & .6074 & .2808 & .1020 & .0098 & .9719 & .0261 & .0020 \\
\hline C56 & .6221 & .2744 & .0952 & .0083 & .9700 & .0280 & .0020 \\
\hline C57 & .6370 & .2679 & .0873 & .0078 & .9688 & .0287 & .0015 \\
\hline C58 & .6669 & .2436 & .0825 & .0070 & .9687 & .0297 & .0016 \\
\hline
\end{tabular}




\begin{tabular}{|c|c|c|c|c|c|c|c|}
\hline \multirow{2}{*}{ Cohort } & \multicolumn{4}{|c|}{ All women, $\mathrm{i}=$} & \multicolumn{3}{|c|}{ Single women, $\mathrm{i}=$} \\
\hline & 0 & 1 & 2 & $3 \leq$ & 0 & 1 & $2 \leq$ \\
\hline \multicolumn{8}{|l|}{$x=26$} \\
\hline $\mathrm{C} 45$ & .2628 & .3314 & .3188 & .0870 & & & \\
\hline C46 & .2637 & .3453 & .3090 & .0820 & & & \\
\hline $\mathrm{C} 47$ & .2756 & .3417 & .3069 & .0758 & .9548 & .0373 & .0079 \\
\hline C48 & .2831 & .3482 & .2981 & .0706 & .9498 & .0414 & .0088 \\
\hline C49 & .2896 & .3512 & .2945 & .0647 & .9417 & .0496 & .0087 \\
\hline C50 & .3109 & .3520 & .2821 & .0550 & .9319 & .0609 & .0072 \\
\hline C51 & .3234 & .3502 & .2762 & .0502 & .9278 & .0626 & .0096 \\
\hline $\mathrm{C} 52$ & .3509 & .3369 & .2647 & .0475 & .9242 & .0655 & .0103 \\
\hline C53 & .3642 & .3387 & .2571 & .0400 & .9232 & .0693 & .0075 \\
\hline C54 & .3834 & .3389 & .2396 & .0381 & .9162 & .0768 & .0070 \\
\hline C55 & .4034 & .3291 & .2334 & .0341 & .9136 & .0788 & .0076 \\
\hline \multicolumn{8}{|l|}{$x=29$} \\
\hline $\mathrm{C} 45$ & .1546 & .2537 & .4260 & .1657 & & & \\
\hline C46 & .1512 & .2663 & .4289 & .1536 & & & \\
\hline $\mathrm{C} 47$ & .1672 & .2586 & .4339 & .1403 & .9047 & .0800 & .0153 \\
\hline C48 & .1754 & .2688 & .4243 & .1315 & .8940 & .0902 & .0158 \\
\hline C49 & .1825 & .2743 & .4247 & .1185 & .8831 & .0986 & .0183 \\
\hline C50 & .1985 & .2814 & .4136 & .1065 & .8689 & .1140 & .0171 \\
\hline C51 & .2076 & .2867 & .4067 & .0990 & .8607 & .1204 & .0189 \\
\hline C52 & .2336 & .2849 & .3886 & .0929 & .8586 & .1222 & .0192 \\
\hline \multicolumn{8}{|l|}{$x=32$} \\
\hline C45 & .1130 & .1948 & .4617 & .2305 & & & \\
\hline C46 & .1087 & .2058 & .4709 & .2146 & & & \\
\hline C47 & .1232 & .2008 & .4794 & .1966 & .8481 & .1267 & .0252 \\
\hline C48 & .1289 & .2084 & .4748 & .1879 & .8326 & .1374 & .0300 \\
\hline C49 & .1338 & .2232 & .4717 & .1713 & .8215 & .1505 & .0270 \\
\hline \multicolumn{8}{|l|}{$x=35$} \\
\hline $\mathrm{C} 45$ & .0954 & .1713 & .4669 & .2664 & & & \\
\hline C46 & .0903 & .1784 & .4755 & .2518 & & & \\
\hline
\end{tabular}

\section{References}

Andersen, D. (1976). Papirløst samliv blandt de 20-29-årige. SFI-meddelelser no. 18. Teknisk forlag, Copenhagen.

Bertelsen, O. (1981). Den unge familie i 70'erne. SFI-publikation no. 99. Teknisk forlag, Copenhagen. Borgan, $\emptyset$. and Ramlau-Hansen, H. (1983). Demographic incidence rates and estimation of intensities with incomplete information. Statistical research report no. 2, 1983, Institute of Mathematics, University of Oslo.

Braun, H. (1980). Regression-like analysis of birth interval sequences. Demography 17 (2): $207-$ 223.

- and Hoem, J. M. (1979). Modelling cohabitational birth intervals in the current Danish population. A progress report. Working paper No. 24. Laboratory of Actuarial Mathematics, University of Copenhagen.

Calot, G. and Blayo, C. (1982). Recent course of fertility in Western Europe. Population Studies, 1982 (3): 345-372.

Danmarks Statistik. Befolkningens bevægelser (Annual publication including vital statistics and, since 1974, statistics on provoked abortion). Danmarks Statistik, Copenhagen. 
- Statistiske efterretninger (Occasional publication) Statistics on "paperless" cohabitational unions may be found in Series A: 1977 (33), p. 757-760; 1978 (17), pp. 393-398; 1980 (32), pp. 1109-1114; 1981 (33), pp. 1035-1040; 1982 (30), pp. 1050-1055. Danmarks Statistik, Copenhagen.

Finnäs, F. (1980). A method to estimate demographic intensities via cumulative incidence rates. Theoretical Population Biology 17 (3): 365-379.

- (1983). Fertility trends of Swedish women, 1960-1977. A study of birth intervals in selected cohorts of women born between 1927 and 1952. Published in Urval 14, pp. 133-217. Statistiska Centralbyrån, Stockholm.

- and Hoem, J. M. (1979). Cohorts trends in cohabitational birth intervals in Denmark, 1975. Scandinavian Population Studies 5, pp. 196-210. Statistisk Sentralbyrå, Oslo.

- and Hoem, J. M. (1980). Starting age and subsequent birth intervals in cohabitational unions in current Danish cohorts, 1975. Demography 17 (3): 275-295.

Hoem, B. (1979). Fertiliteten efter kvinnans ålder och paritet hos danska kvinnor födda sedan 1945. Working paper No. 8. Copenhagen: Danmarks Statistik.

Hoem, J. M. (1977). A Markov chain model of working life tables. Scandinavian Actuarial Journal 1977, pp. 1-20.

- (1978). Demographic incidence rates. Theoretical Population Biology 14: 329-337.

- and Fong, M. (1976). A Markov chain model of working life tables. Reports no. 1-2 + Supplement. Working papers No. 2 and 4. Laboratory of Actuarial Mathemathics, University of Copenhagen.

- and Funck Jensen, U. (1982). Multistate life table methodology: A probabilist critique. In: Multidimensional mathematical demography edited by K. C. Land and A. Rogers. Academic Press, New York.

- and Rennermalm, B. (1982). Cohabitation, marriage, and firstbirth among nevermarried Swedish women in cohorts born 1936-1960. Stockholm research reports in demography, No. 8. Department of Statistics, University of Stockholm.

- and Selmer, R. (1982). The interaction between premarital cohabitation, marriage, and the first two births in current Danish cohorts, 1975. Stockholm research reports in demography No. 1. Department of Statistics, University of Stockholm.

Jensen, A. M. (1983). Demografisk analyse af individ-data fra Kenya Fertility Survey 1977/78. Unpublished master thesis, Institute of Economics, University of Copenhagen.

Johansson, L. (1983). Cohort fertility by age and parity of Swedish women born 1930-1960. Published in Urval 14, pp. 5-131. Statistiska Centralbyrån, Stockholm.

Koch-Nielsen, I. (1975). Ægteskabet og loven. SFI-publikation no. 66. Teknisk forlag, Copenhagen.

Rachootin, P. and Olsen, J. (1982). Prevalence and socioeconomic correlates of subfecundity and spontaneous abortion in Denmark. International Journal of Epidemiology 11 (3): 245-249.

Rasmussen, N. K. (1983). Abort - et valg? Publication no. 15, Institute of Social Medicine. Copenhagen; FADL's forlag.

Rohrmann, D. (1983). En demografisk analyse af udviklingen i fødselstallet i Danmark 1946-1981 som funktion af indgåelse og opløsning af ægteskab samt alders- og civilstandsbetinget reproduktiv adfærd. Unpublished master thesis, Institute of Economics, University of Copenhagen.

Selmer, R. M. (1983). Samliv uten vigsel - ekteskap og fødsler. Artikler 146. Statistisk Sentralbyrå, Oslo; in commission at $\mathrm{H}$. Aschehoug \& Co. and Universitetsforlaget, Oslo.

Strandmark, L. (1982). Den danske arbejdsstyrkes bevægelser 1972-1979. Unpublished master thesis, Institute of Economics, University of Copenhagen. An abbreviated version of this work is forthcoming in Okonomi og Politik, 1984.

Sundhedsstyrelsen (1975 ff.). Statistik om prævention og aborter, $1974 \mathrm{ff}$. Sundhedsstyrelsen, Copenhagen.

Ussing, J. (1979). Om abort. SFI-rapport no. 87. Teknisk forlag, Copenhagen. 